\title{
OBSERVATIONS AND MEASUREMENTS OF WING PARAMETERS OF THE SELECTED BEETLE SPECIES AND THE DESIGN OF A MECHANISM STRUCTURE IMPLEMENTING A COMPLEX WING MOVEMENT
}

\author{
T. GEISLER \\ Institute of Mechanics and Machine Design Foundations \\ The Faculty of Mechanical Engineering and Computer Science \\ Czestochowa University of Technology \\ ul. J.H. Dąbrowskiego 73, 42-200 Częstochowa, POLAND \\ E-mail: geisler@imipkm.pcz.pl
}

\begin{abstract}
Beetle wings perform a flapping movement, consisting of the rotation relative to the two axes. This paper presents the results of observations and measurements of wings operating parameters in different planes of some beetle species. High speed photos and videos were used. The concept of the mechanism performing a complex wing movement was proposed and developed.
\end{abstract}

Key words: biomimicry, wing, flapping mechanism, parameters.

\section{Introduction}

The aim of the study was to investigate the behavior of wings during the flight of selected beetle species. The observations allowed the measurement of the wings operating parameters in a three-dimensional space. Both the observations of insect behavior during flight and the wing measurements allow an understanding of solutions found in nature. The functioning of the flying insects can be an inspiration to the bionic design of various machines, including micro air vehicles (MAV). Bionics as an interdisciplinary science includes structural and functional analysis of living organisms in order to adapt nature's solutions in the technology.

Research focused on mechanically reproducing wings of various species has been extensively developed recently. In the literature, papers on the analysis of the structure and folding wings of both beetles and other insects can be found. The works [1] and [2] are examples of the beetle wing construction usage in the construction of a micro flying model that mimics wing movement. An analysis of wing cover closing and rotation mechanism of many beetle families was described in [3], [4], [5]. A number of works concerns the construction of flying insect models. In the paper [6] a transmission mechanism design for a micro flying insect was presented, and in the paper [7] measurements of angles and forces of a transmission mechanism model were shown. Currently in Poland, studies regarding kinematics and aerodynamic load the insects' wings are underway [8], [9]. In the paper [10] an analysis of the aerodynamic forces acting on the wings of a miniature aerial vehicle - entomopter, was presented. Observations of the beetles' wings behavior are the subject of many papers. In the paper [11], the behavior of the wings during the unfolding motion based on the beetle Pachnoda marginata KOLBE, 1906, was analyzed. In the work [12], wing motion of the beetle Allomyrna dichotomia (L., 1771) was analyzed. A preliminary analysis of the construction and structure was made, as well as model devoid of an accurate mapping of the geometry and stiffness was proposed. In the paper [13] observations of the Allomyrna dichotomia beetle, wing movement parameters and a simplified wing mechanism were included. 
In the work [14], a prototype of the wing drive mechanism, wing research in water tunnel as well as delimitation of wing working area were presented. In the paper [15], a wing structure (morphology) of Allomyrna dichotomia was presented. A wing folding mechanism based on the articulated quadrilateral (rotary pairs) and the wing flapping drive mechanism were proposed. A model was built and tested. In an interesting paper [16] MAV mechanism using a four-bar linkage mechanism for the transfer of power on the wings of elastic components was proposed.

A schematic design of a mechanism and its research were included in the paper [17]. The mechanism was based on the structure of insects of which the wing drive comes from the musculo - skeletal system, especially from the movement (deformation) of thorax scleritis. In the work [18] different flapping mechanisms used for hummingbird models, were presented.

Mechanisms based on the articulated quadrilateral may also find application in the MAV construction based on beetles structure. In the study [19], the mechanism implementing a flapping motion combined with rotation was presented and experimentally tested. Also, a visualization of a vortex around rectangular wings in the air and vacuum was shown. The paper [20] verified several flapping mechanisms including a four-bar linkage and the usage of toothed rack and spherical kinematic pairs to forward propulsion. In the work [21], the design of the MAV driven by a four-bar linkage mechanism and aerodynamic performance for a flat wing membrane panel were presented. In the paper [22], the construction of MAV's wing drive mechanism using MEMS technology was shown. The proposed model was tested in a wind tunnel with a measuring system. Field observations were also made.

In this paper, a diagram of the mechanism systems implementing the complex wing movement was proposed. Assumptions were have been made and different versions of drive transmission and wing rotation were developed. Mechanism's components were listed, kinematic pairs and their classes were adopted. This paper is a continuation of the research done in the field of application of bionic solutions of nature.

\section{Structure and functions of beetle wings}

The main function of the wings is flight. Wing structure is complicated and must ensure its full functionality. The main components of the wings are membranes, veins, nerves and veins with circulating hemolymph. Chitin is the main component of insects' skeletal body and the wings. The largest wing area consists of a flexible and durable system of two membranes. The combination of membranes and veins creates a large bearing surface of the wing, with a minimum weight. Wing weight of various beetles indicated in paper [23] varies in the range of $1-2.5 \%$ by weight of the entire insect and the weight of the covers is $3-8 \%$ of the entire insect weight. A number of wing features derives from the possibility of folding, bending and hiding under the covers. In the study [24] the structure and analysis of the Xylotrupes gideon (L., 1767) beetle was presented. The analysis methodology and internal wing structure description was proposed. Beetles' flight, of the analyzed Cetoniinae family, is possible due to the flapping wing movement. This movement is made of both the flapping movement along the longitudinal body axis and the rotational movement around the wing axis. A complex flapping movement enables motion drive, ascent and the change of direction. Wing movement is done by operating dorsal muscle and the elastic deformation of the torso sclerites. The thoracic segment is composed of four sclerites: dorsal - tergum, abdominal - sternum and two lateral - pleurites. Wings are attached between the tergite and pleuryte and legs are located between pleuryte and sternite. Muscle support is given by the thorax sclerites - a very complicated structure. The inner space of the body, especially in the flying forms, is almost entirely filled with muscle mass [25].

A complex musculoskeletal drive mechanism is responsible for wing motility and is associated with the body of an insect and the joint mechanism. Transferring the movement on the wing is done using tergit and sternit movements as well as the subalar and basalar muscles. Among the analyzed beetle family the first pair of wings has transformed into hard covers (elytra) protecting the hindwings hidden beneath highly sclerotized forewings. Covers serve as protective wing-cases for the abdomen. During the flight covers evade permitting spread and flapping of the hind wings. In the study [26], structures responsible for folding and locking wings upon reaching the maximum deflection angle of the wing leading edge were described. The 
morphology and physiology of insects as well as the entomological concepts were described in the literature [25], [27], [28], [29].

Wing folding and unfolding observations made with the usage of video recordings were presented in the papers [30] and [31]. The wing spreading effect in the bending joint is the result of hemolymph pressure changes in the veins and the elasticity of the wing structures.

In the paper [32], wing folding and tucking on the thorax under the covers as well as the position of the antennae and legs during launch and flight of an insect were researched. Balancing using legs may change the center of gravity and help control the direction of flight. The behavior of the opening and evading covers and wings of some beetle species were shown in the paper [33].

\section{Examined beetle species}

The beetle species examined and observed belong to the order Coleoptera, Scarabaeidae family and Cetoniinae subfamily. The beetle species, whose behaviour was analyzed, are listed below:

Mecynorrhina torquata ugandensis (MOSER, 1907), $\{\mathrm{Mtu}\}$, Mecynorrhina torquata immaculicollis (FABRICIUS, 1775), \{Mti\}, Chelorrhina polyphemus confluens (KRAATZ, 1890), \{Cpc\},

Dicronorrhina derbyana conradsi KOLBE, 1909, \{Ddc $\}$,

Eudicella trilineata (QUDENFELD, 1880), $\{\mathrm{Et}\}$,

Eudicela aethiopica MÜLLER, 1941, \{Ea\}, Megalorrhina harrisi WESTWOOD, 1847, $\{\mathrm{Mh}\}$, Cetonia aurata aurata (LINNAEUS, 1758), \{Caa $\}$.

The main object of the study and observation were beetles of the subfamily Cetoniinae that belong to species that repeals covers to spread wings. In order to simplify the description, later in the paper, references were introduced, for example: beetle $\{\mathrm{Mtu}\}$. In case of a female insect, $\mathrm{f}$ (female) letter was introduced, for example: $\{\mathrm{Mtu}(\mathrm{f})\}$. The researched beetles belong to a family in which the heaviest species of beetles are classified. For example, beetles of the genus Goliatus can reach $110[\mathrm{~mm}]$ in length and weigh approximately $50[\mathrm{~g}]$. Selected beetle species reached a body length of 22 to $70[\mathrm{~mm}]$, a wingspan of $50 \div 125[\mathrm{~mm}]$ and weight from 0.5 to $10[\mathrm{~g}]$.

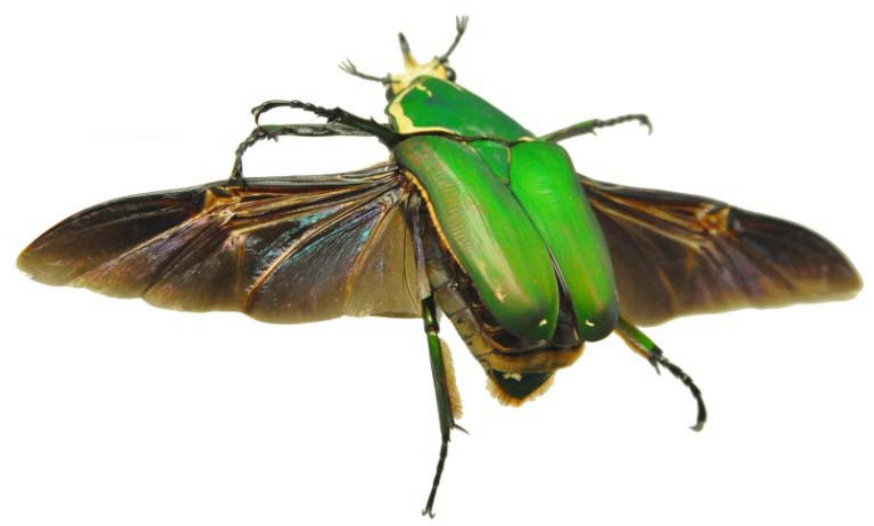

Fig.1. Mecynorrhina torquata immaculicollis beetle (F., 1775).

Studied beetles are native to Africa, with the exception of species native to Poland (Cetonia aurata a. (L., 1758)). All studied insects were bred by the author. Whenever possible, both male and female beetles were observed and measured. Sexual dimorphism was visible and was characterized by the presence of horns on the head and different body proportions of exotic species. In addition, beetles from the subfamily Melolonthinae and families Cerambycidae, Geotrupidae and Carabidae, which evade covers during the flight, were also observed. However, more observations and measurements are required. 


\section{Observation and measurement of beetle's wing working parameters}

Wing tilting angle measurements were performed in multiple planes. Also the body location during flight observations and angle of attack measurements were performed. The flapping frequency was also determined. Wing structure, folding and bending patterns of different beetle species were discussed in the paper [34].

Production of driving force during flight is associated with a complex movement of the rear wings. Wing's inclination and twist changes depend on muscle work and sclerite deformation and derive from the variable flexibility (elasticity) of the membrane.

The wing is characterized by an uneven distribution of mass and stiffness in the longitudinal and transverse directions. This is due to the variable veins rigidity and distribution of facets in the membrane structures. Wing stiffness also depends on the hemolymph pressure inside inner veins.

During the movement, the wing is subject to deformations arising from air resistance. Wing surface tilting varies depending on the phase position of the wing and is essential for the mechanism of flight. During the downward movement, the wing strikes due to a strong contraction of the longitudinal muscle of the thorax. The wing hits the air using the entire width (surface). The reverse wing movement causes a strike from the front towards the rear of the insect. It is caused by a contraction of strong dorso - abdominal muscles. During this contraction, the upper surface (dorsal) gets twisted [25].

Based on the observations of living beetles, basic wing parameters of selected beetles were indicated. Determination of the wing structure position angles (absolute and relative) was possible. It was also possible to determine the movement time of individual phases of the wing position as well as the flapping frequency.

The phantom Miro EX4 camera was used for video recording movies (.cine extension). The practical resolution usage is between $512 \times 256(\sim 4400[f p s])$ up to $256 \times 128(\sim 15000[f p s])$. Selected observations were also conducted for speeds: $\sim 1900, \sim 43000$ and $\sim 59000[\mathrm{fps}]$. In order to record videos and take photographs NIKON cameras (systems: DX, FX) with micro/macro lenses and accessories were also used. The CASIO EX-ZR camera with the possibility of recording images and video at a speed of 30-1000 [fps] was used.

All observations of the wings movement were made using living imago insects. Insect observations were made in a specially designed positioning system. The study did not cause any damage to the beetles. Free start and flight of insects was also observed. Fulfillment of Certain conditions was required to cause wing spreading and to encourage the beetles to flapping. The correct temperature $\left(>24^{\circ} \mathrm{C}\right)$, humidity $(50$ $60 \%)$ and stimulation of the insects were required. The day part as well as the intensity of natural and artificial light in the observation area was also important. This was achieved through the use of photographic light bulbs for a total luminous flux of $\sim 28000[\mathrm{~lm}]$ and the power of $\sim 2000[\mathrm{~W}]$.

Deflection angle measurements were performed at different levels for various veins positions: costal, subcostal and the radius $(\mathrm{C}+\mathrm{Sc}+\mathrm{R} 1),[23],[25],[28],[29]$. These are the stiffest wing structures forwarding the musculoskeletal system movement to the remaining wing structures. While in motion, veins and membranes undergo elastic deformation. Observation and measurement of the wing position were made in two vertical planes perpendicular to each other.
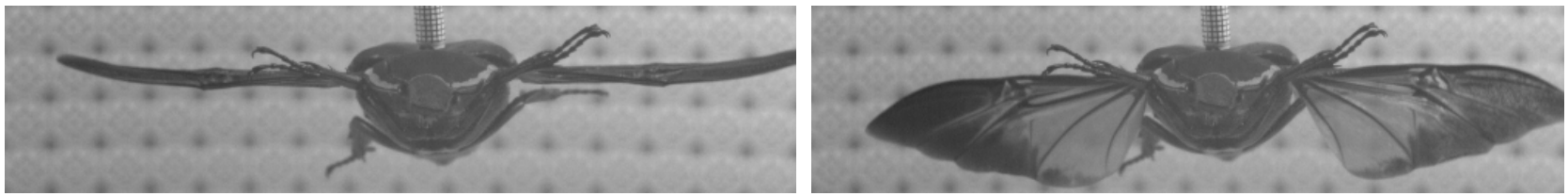

Fig.2. Mecynorrhina torquata ugandensis beetle (M, 1907), front view. 

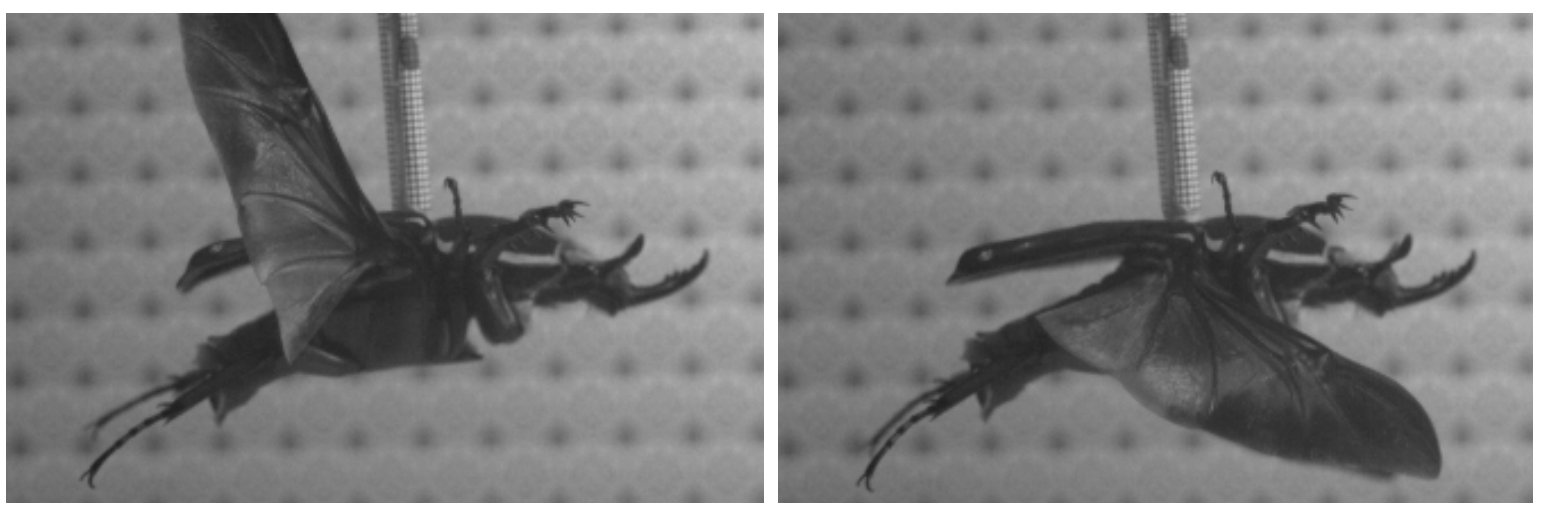

Fig.3. Mecynorrhina torquata ugandensis beetle (M, 1907), side view.

The first plane was perpendicular (transverse) to the longitudinal axis of the insect (Fig.2). In this plane, the wing $(\mathrm{C}+\mathrm{Sc}+\mathrm{R} 1$ vein system) position angles were measured in front and back of the beetles. The second vertical plane (longitudinal) was normal thereto and was used to measure wing position angle changes of the side of insects (Fig.3.). Photos and videos of the bottom of the beetle in a free flight were also taken. Measurements were also made for the veins projections on the adopted measurement planes.

Points and lines on the beetles' body, along which the positions of selected wing structures were considered, were adopted. The point adopted for the longitudinal axis was placed on the wing joint. The longitudinal axis was also marked with the point on top of the penultimate segment of the abdomen. For the measurements in the first plane, extreme points on beetles pronotum were used. For the angle values of this plane, upward and downward movement designations $\left(\alpha_{1}\right)$ and $\left(\alpha_{2}\right)$, respectively, were used (Fig.4). And for the angles along the longitudinal plane $\left(\beta_{1}\right)$ and $\left(\beta_{2}\right)$ movement designations were used.

The knowledge of the structure and observations made while preparating insects was helpful in measurement point's adoption. The body positioning during flight referred to as the angle of attack is an important parameter. The angle of attack $(\delta)$ varies and depends on the nature of the flight (Fig.5). It is greater during elevating and smaller during a level flight.

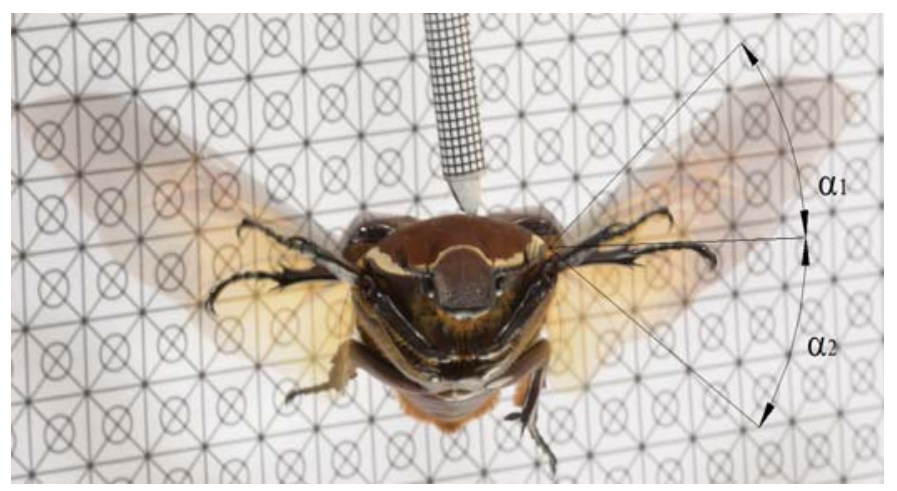

Fig.4. Range of angles in a transverse plane of a beetle $\{\mathrm{Mtu}(\mathrm{f})\}$. 


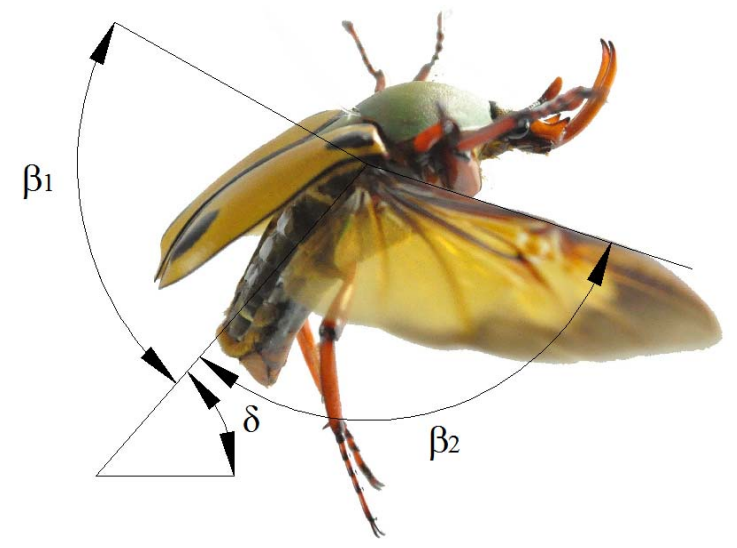

Fig.5. Range of angles in a vertical plane of a beetle $\{\mathrm{Et}\}$.

The location of the insect's body is changing in relation to the location of the hidden wings. During flight covers are slightly opened $\left(8-18^{\circ}\right)$ in relation to the rest position measured from the bending like of the abdomen downwards.

During the wing work of $\{\mathrm{Mtu}\}$ beetles and others, a separation of the covers is present in the lower section in about $1 / 5$ of the length of the cover. The synchronized cover and wing movement is also visible [33]. For one of the beetles, it was observed that the absence of a leg caused wing dysfunction. Damage of one of the veins also causes a change in the wing functioning. For these cases, photo and video registration was done.

The table (Tab.1) shows the wing's veins structure position angle values, with an error of $\pm 5^{\circ}$, and the angle of attack $(\delta)$ mean values with the deviation of $\pm 15^{\circ}$.

Angle values depend on the species and size of the beetle. The values are similar for different species. Measurements were subject to errors resulting from the different position of the camera's optical axis relative to the axis of the insect, as well as deviations relative to the adopted measurement planes. The measurements need to be confirmed for a larger number of beetles.

Table 1. The values of angles.

\begin{tabular}{|c|c|c|c|c|c|c|c|}
\hline \multirow{2}{*}{ species } & \multicolumn{7}{|c|}{ angle $\left[{ }^{\circ}\right]$} \\
\cline { 2 - 8 } & $\alpha_{1}$ & $\alpha_{2}$ & $\alpha=\alpha_{1}+\alpha_{2}$ & $\beta_{1}$ & $\beta_{2}$ & $\beta=\beta_{1}+\beta_{2}$ & $\delta$ \\
\hline $\mathrm{Mtu}$ & 42 & 38 & 80 & 83 & 118 & 201 & 44 \\
\hline $\mathrm{Mtu}(\mathrm{f})$ & 42 & 25 & 67 & 67 & 132 & 199 & 41 \\
\hline $\mathrm{Mti}$ & 54 & 33 & 87 & 67 & 118 & 185 & 39 \\
\hline $\mathrm{CPc}(\mathrm{f})$ & 32 & 35 & 67 & 78 & 126 & 204 & 47 \\
\hline $\mathrm{Ddc}$ & 37 & 23 & 60 & 74 & 137 & 200 & 43 \\
\hline $\mathrm{Et}$ & 45 & 30 & 75 & 77 & 120 & 197 & 48 \\
\hline $\mathrm{Et}(\mathrm{f})$ & 55 & 27 & 82 & 79 & 123 & 202 & - \\
\hline $\mathrm{Ea}$ & 32 & 24 & 56 & 73 & 112 & 185 & 37 \\
\hline $\mathrm{Mh}$ & 54 & 37 & 91 & 69 & 140 & 209 & 34 \\
\hline $\mathrm{Caa}$ & 59 & 25 & 84 & 59 & 129 & 188 & 39 \\
\hline
\end{tabular}

For the external dimensions measurements, measuring points were introduced. Along the insects body, distances between points on the pronotum beginning and the cover end $(h)$, as well as points on the basis of the target plate to the cover end (l) were measured (Fig.6). The body length is determined by the $(m)$ 
dimension. A transverse dimension was defined as the distance between the extreme points of the pronotum $(s)$. The spread is determined by the $(w)$ dimension. Height $(g)$ was also measured.

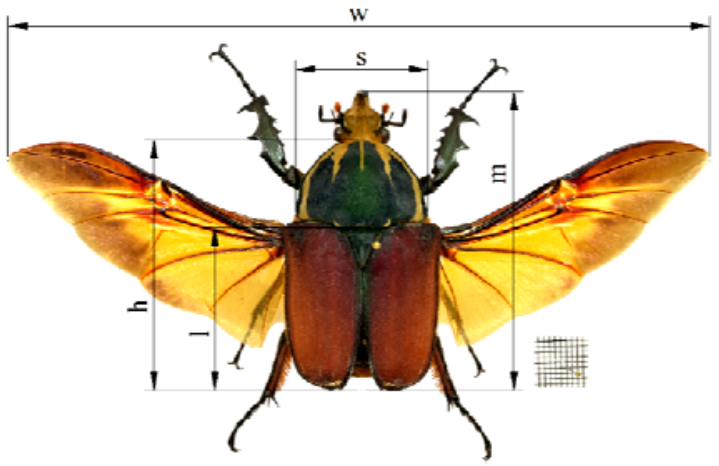

Fig.6. Beetle $\{\mathrm{Mtu}(\mathrm{m})\}$, dimensions.

For example, for one of the male beetles $\{\mathrm{Mtu}\}$ the measured sizes were: $m=60, h=46.8, l=31.6$, $s=24.7, w=127.3, g=16.8[\mathrm{~mm}]$ and for the female $\{$ Mtu (f) $\}: m=55, h=46.9, l=32.7, s=23.7, w=127$, $g=16.8[\mathrm{~mm}]$, weight $\sim 10[\mathrm{~g}]$. For the smallest beetle tested $\{\mathrm{Caa}\}$ the sizes were: $m=22.5, h=20, l=14.8$, $s=10.3, w=53.8, g=8.1[\mathrm{~mm}]$, weight $0.55[\mathrm{~g}]$.

During the downward movement the wings membrane is parallel to the insect's body, while during the upward movement, wings membrane deforms (twists) considerably more than in the downward movement (Fig.2). This is due to the variable stiffness of veins, structures and wings membranes relative to the vein system $(\mathrm{C}+\mathrm{Sc}+\mathrm{R} 1)$. Movement of the main membrane surface can be regarded as a twisting motion in a transverse direction to the rigid vein system. For the individual rigid veins system position, the rotation angle of the membrane can be determined. Also a wing deformation in the longitudinal direction resulting, among others, from a drag force, can be noticed (Fig.7).

A wing partial deflection in the joint during the upward movement was also observed. In the picture (Fig.7) beetle's $\{$ Mtu (f) $\}$ membrane position and its deflection during downward movement is visible. In the picture (Fig.8) beetle's $\{$ Mtu (f) $\}$ membrane position during the upward movement is visible.

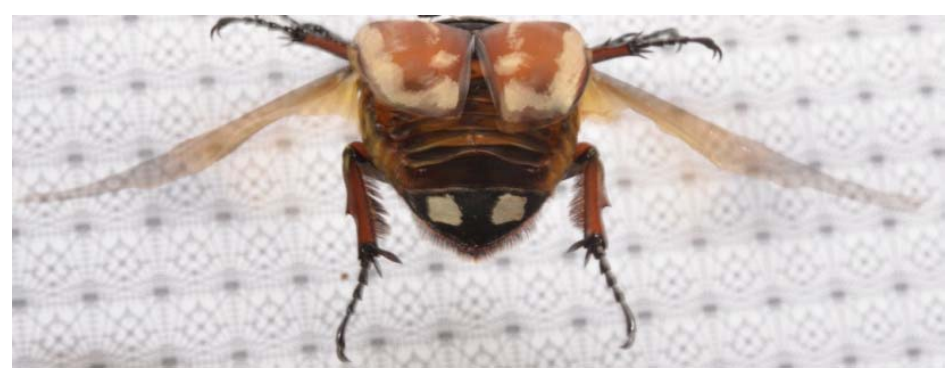

Fig.7. Beetle $\{$ Mtu (f) $\}$, back view.

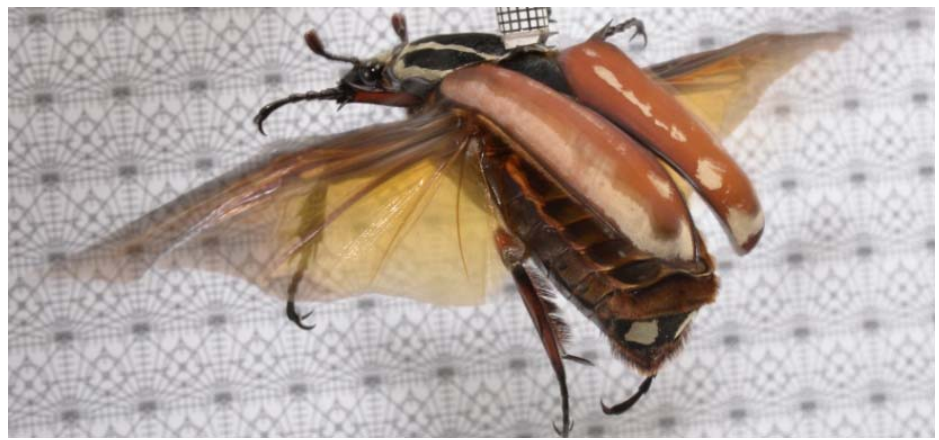

Fig.8. Beetle $\{$ Mtu (f)\}, top view. 
The individual time phases of wing movements were measured. Wing flapping frequency was determined. They amounted to $\{\mathrm{Mtu}\}$ 51.1-58. $5[\mathrm{~Hz}]$, for male beetles females \{Mtu (f) $\}$ 54.1-57.3 [Hz], male $\{\mathrm{Mh}(\mathrm{m})\} \sim 64.8[\mathrm{~Hz}]$, male $\{\mathrm{Ea}(\mathrm{m})\}$ 76.1-77.1 [Hz], male $\{\mathrm{Et}(\mathrm{m})\}$ 80.2-83.2 [Hz], females $\{\mathrm{Et}(\mathrm{f})\}$ $73-75.3[\mathrm{~Hz}]$ and male $\{\mathrm{Caa}(\mathrm{m})\} \sim 99.7[\mathrm{~Hz}]$. For most of the researched beetles a different time of stroke in the upward and downward movement was found. Downward wing movement was longer than the upward movement. For beetles: $\{\mathrm{Mh}(\mathrm{m})\}+0.7 \%$, $\{\mathrm{Mtu}(\mathrm{f})\}+17.7 \%$, $\{\mathrm{Et}\}$ to $+22 \%$. Measurements need to be confirmed for a larger number of species and specimens of beetles.

\section{The concept of mechanism implementing a complex wing movement}

It is possible to bionically reproduce mechanical structures based on the analysis and measurements of various operating parameters of the wings of insects (beetles). The system structure adoption consists in the identification of links, kinematics pairs and their degrees of freedom [35], [36], [37], [38]. The considered mechanism was adopted as mechanism with a complex structure. In the mechanism two basic areas of main components movement, parallel to each other, can be separated. Flapping wing movement is complex. The angular velocities of the drive component (2) and the ratio (2'-3) depend on the selected motor.

In the scheme (Fig.9) a part of the adopted mechanism's structure was shown. The rod (4) along with the yoke performs a reciprocating motion in a vertical plane. It is associated with the connector (5), which causes movement of the component (6) forcing the flapping movement of wings (7).

Wing movement (flapping) is a complex movement consisting of flapping and rotation. Rotation is allowed by the intermediate component (9). It is connected to the components (7) and (11) by the kinematics pairs (nodes 8,10 ).

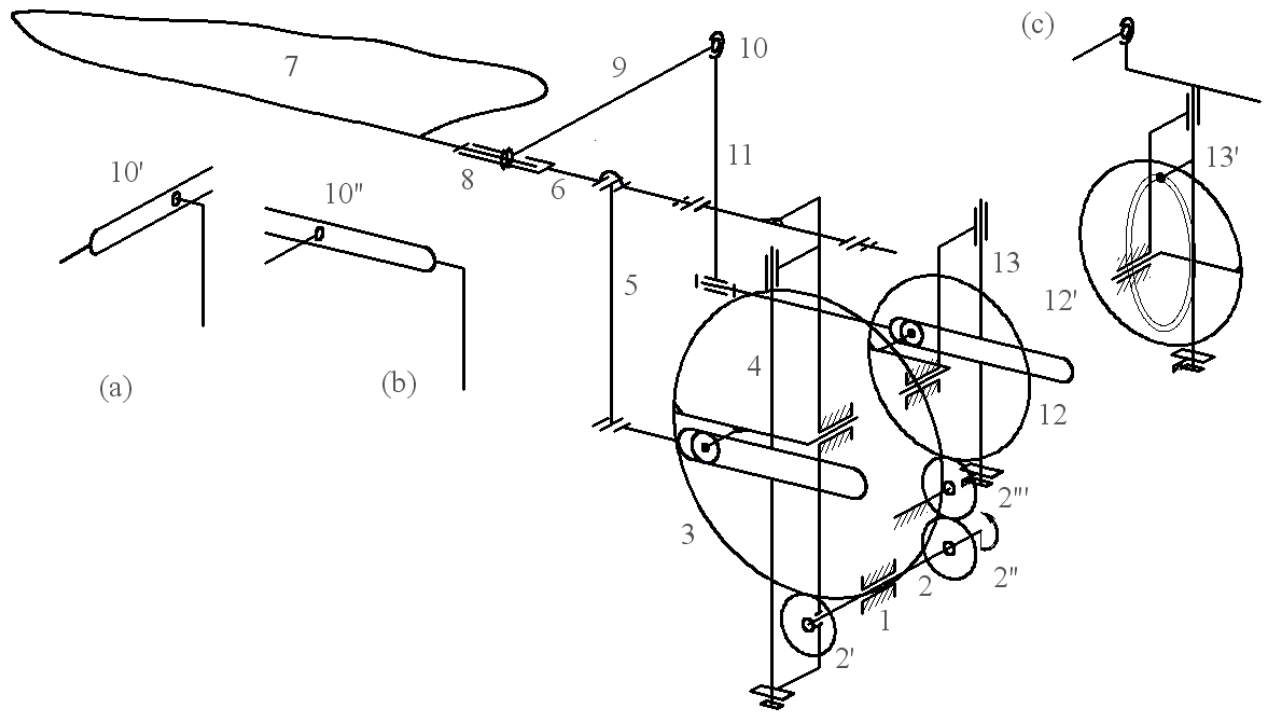

Fig.9. Structure of the flapping mechanism.

A kinematic pair (8) should enable the rotating movement relative to the component (6) with an angle of wing rotation designated on the basis of observation. Rotational movement may be obtained using the second yoke mechanism, containing components (12) and (13). The drive is obtained from the transmission associated with a drive (2). The drive system of the transmission (2-2"-2"') can be selected to yield a required rotational speed of the wheel (12). The kinematic pairs forming the local degrees of freedom are present in the mechanism. They are formed, for example, by the rollers in the yokes rods $(4,13)$. These are examples of design solutions. Rods have one degree of freedom. 
A kinematic pair (10) as a combination of component (9) and (11) can be modified. It can be replaced with kinematic pairs containing a spatial yoke component with two degrees of freedom. The solutions were illustrated in schemes (Fig.9a), (Fig.9b) in which the rod within the yoke can slide and rotate with respect to the axis of the yoke (with slack). When using a spatial yoke in the kinematic pair (10), the kinematic pair (8) may have one degree of freedom. It is possible to obtain a rotational movement of wing similar to the real movement of the researched beetles. The proposed mechanism with the closed cam (12'13') allows a complex returning motion of the wings (Fig.9c). A returning movement of member (9) in the extreme positions of the specified angular velocity will be possible. During the downward wing movement, the cam mechanism keeps the angle ensuring a maximum aerodynamic force.

During the wing movement, it is possible to obtain a wing tilt, similar to the behaviour of the observed beetles. To obtain a variable angle of the wing surface relative to the vein system, it is necessary to introduce components with varying rigidity (torsion) and locks in a direction transverse to the axis of the wing. It is possible to introduce additional mechanisms to control folding and bending the wings on the component (9). Adding, for example, mechanism of wing folding will require the development of a more complex mechanism and the inclusion of an additional drive. In the transfer of power on the wing, locking mechanisms are planned to be used [34].

Based on the presented concept, a mechanical structure of the mechanism can be developed. Due to the construction and strength it will be necessary to introduce kinematically redundant components, for example in the construction of kinematics nodes $(6,8)$. In the design of the mechanism the following assumptions were made: low weight, minimizing the number of components, one drive, its low cost and simple installation.

\section{Summary}

The paper required the knowledge of many aspects of morphology and physiology of insects. The out observations carried out may assist in designing the wing drive mechanism of bionic models. During the measurements of beetle's working wings, wing structure position angles were determined, and the frequency of their work was calculated. The obtained angle values made it possible to define wing working area relative to the insect's body.

A significant change in the behaviour of the membrane against the rigid vein system $(\mathrm{C}+\mathrm{Sc}+\mathrm{R} 1)$ depending on the direction of impact was observed. Wing surface tilting varies depending on the phase position of the wing and is essential for the mechanism of flight. The geometric dimensions of the studied beetles were also made.

The concept of the mechanism performing the complex movement of flapping wings was proposed. The construction of the complex drive mechanism can be based on the construction of real insects and parameters of the structure of the wings. To obtain the proper behaviour of wings in the construction of drive transmission, the stiffness asymmetry of the components should be taken into account.

The design of the mechanism and its versions should consider the obtained parameters of researched beetle's wing and work with the determine wing flapping frequency. The possibility of adding a mechanism of wing folding and bending control was pointed out.

Imitating nature solutions (bionics, biomimicry) greatly facilitates the construction of bionic mechanical design. The results of observations and parameters obtained can be used to develop the design and construction of flying models (MAV). It is possible to design objects of miniaturized construction. It is planned to build prototypes of drive mechanisms and further research their aerodynamic behaviour in a wind tunnel.

\section{References}

[1] Bhayu P.R., Nguyen Q.V., Park H.C., Goo N.S. and Byun D. (2010): Artifical Cambrered-Wing for a BeetleMimicking Flaper. - Journal of Bionic Engineering, 7 Suppl, pp.S130-S136. 
[2] Nguyen Q.V., Park H.C, Goo S.G. and Byun D. (2010): Characteristics of a Beetle's Free Flight and a FlappingWing System that Mimics Beetle Flight. - Journal of Bionic Engineering. 7 Suppl., pp.77-86.

[3] Frantsevich L. (2011): Mechanisms Modeling the Double Rotation of the Elytra in Beetles (Coleoptera). - Journal of Bionic Engineering, vol.8, pp.395-405.

[4] Frantsevich L. (2012): Double rotation of the opening (closing) elytra in beetles (Coleoptera). - Journal of Insect Physiology, vol.58, pp.24-34.

[5] Frantsevich L. (2012): Indirect closing of elytra by the prothorax in beetles (Coleoptera): general observations and exceptions. - Zoology, vol.115, pp.12-21.

[6] Fenelon M.A.A. and Furukawa T. (2010): Design of an active flapping wing mechanism and a micro aerial vehicle using a rotary actuator. - Mechanism and Machine Theory, vol.45, pp.137-146.

[7] Nguyen Q.V., Truong Q.T., Hoon Park H.C, Goo S.G. and Byun D. (2010): Measurement of Force Produced by an Insect-Mimicking Flapping-Wing System. - Journal of Bionic Engineering, 7 Suppl., pp.S94-S102.

[8] Czekałowski P. and Sibilski K. (2012): Influence of cruise flight speed of entomopter on aerodynamics loads. Gliwice: Modelling in Engineering, vol.45. No.14, pp.206-212.

[9] Czekałowski P. (2009): Investigation of the Entomopter's wings movement kinematics on its performance - the general concept of research. - Modelling in Engineering, vol. 37, pp.71-76, Gliwice.

[10] Jaroszewicz A. (2009): Modeling and simulation of flight dynamics entomopter. - Modeling in Engineering, vol.38, pp.77-85, Gliwice.

[11] Haas F. and Beutel R.G. (2001): Wing folding and the functional morphology of the wing base in Coleoptera.Zoology, vol.104, pp.123-141.

[12] Muhammad A., Nguyen Q.V., Park H.C, Hwang D.Y., Byun D. and Goo S.G. (2010): Improvement of artificial foldable wing models by mimicking the unfolding/folding mechanism of a beetle hind wing. - Journal of Bionic Engineering, 7 Suppl, pp.134-141.

[13] Phan H.V., Nguyen Q.V., Truong Q.T., Truong T.V., Park H.C., Goo N.S., Byun D. and Kim N.J. (2012): Stable vertical takeoff of an insect-mimicking flapping-wing system without guide implementing inherent pitching stability. - Journal of Bionic Engineering, vol.9, pp.391-401.

[14] Czekałowski P., Nowakowski M., Sibilski K., Żyluk A. and Wróblewski W. (2014): Neural model of an entomopter aerodynamics. AIAA Atmospheric Flight Mechanics Conference, AIAA SciTech, - AIAA $2014-0893$.

[15] Truong Q.T., Argyoganendro B.W. and Park H.C. (2014): Design and demonstration of insect mimicking foldable artificial wing using four-bar linkage systems. - Journal of Bionic Engineering, vol.11, No.3, pp.449-458.

[16] Dawson J.C. and Huang P.G. (2011): Figure-8 flapping micro air vehicle. 49th AIAA Aerospace Sciences Meeting Including the New Horizons Forum and Aerospace Exposition 4 - 7 January 2011, Orlando, Florida, AIAA 2011-551.

[17] Khan Z.A. and Agrawal S.K. (2011): Study of biologically inspired flapping mechanism for micro air vehicles. AIAA JOURNAL, vol.49, No.7, July 2011, pp.1354-1365.

[18] Keennon M., Klingebiel K., Won H. and Andriukov A. (2012): Development of the nano hummingbird: a tailless flapping wing micro air vehicle. - 50th AIAA Aerospace Sciences Meeting including the New Horizons Forum and Aerospace Exposition 09 - 12 January 2012, Nashville, Tennessee, - AIAA 2012-0588.

[19] Seshadri P., Benedict M. and Chopra I. (2013): Understanding Micro Air Vehicle Flapping-Wing Aerodynamics Using Force and Flowfield Measurements. - Journal of Aircraft, vol.50, No.4, July-August 2013, pp.1070-1087.

[20] Oppenheimer M.W., Sigthorsson D.O., Weintraub I.E., Smith T.J., Dawson J.C. and Doman D.B. (2013): Development of a Flapping Wing Mechanism That Can Produce Lift Greater Than Weight. Guidance, Navigation, and Control and Co-located Conferences, August 19-22, 2013, Boston, MA, - AIAA 2013-5106.

[21] Tsai B.J. and Fu Y.C. (2009): Design and aerodynamic analysis of a flapping-wing micro aerial vehicle. Aerospace Science and Technology 13 pp.383-392. 
[22] Yang L.J., Hsu C.K., Ho, J.Y. and Feng C.K. (2007): Flapping wings with PVDF sensors to modify the aerodynamic forces of a micro aerial vehicle. - Sensors and Actuators A 139, pp.95-103.

[23] Geisler T. (2011): Construction and wing folding of selected families of beetles (Coloptera). - Czestochowa Entomological Circle Bulletin, No.10, pp.12-21.

[24] Geisler T. (2012): Analysis of the structure and mechanism of wing folding and flexion in Xylotrupes gideon beetle (L. 1767) (Coloptera, Scarabaeidae). - Acta Mechanica et Automatica, vol.6, No.3, pp.37-44.

[25] Szwanwicz B. (1956): General Entomology. - Warsaw: PWRiL.

[26] Geisler T., Rosikoń P., Sochacki W. and Topczewska S. (2014): Functional and Structural Analysis of Wing Folding Mechanism Based on Cockchafer (Melolontha melolontha). - Acta Mechanica et Automatica, vol.8. No.3, pp.129-135.

[27] Pławilszczikow N. (1968): Keys for Identifying Insects. - Warsaw: PWRiL.

[28] Razowski J. (1987): Entomological Dictionary. - Warsaw: PWN.

[29] Razowski J. (1996): Dictionary of Insect Morphology. - Warsaw-Krakow: PWN.

[30] Dudley R. (1999): The Biomechanics of Insect Flight: Form, Function, Evolution. - New Jersey: Princeston University Press.

[31] Sun J., Ling M., Wu W., Bhushan B. and Tong J. (2014): The hydraulic mechanism of the unfolding of hind wings in dorcus titanus platymelus (order: coleoptera). - International Journal of Molecular Sciences, vol.15, pp.60096018.

[32] Geisler T. (2014): Wing functionality observation of the selected beetle species (Coleoptera: Scarabaeidae, Cerambycidae). - Czestochowa Entomological Circle Bulletin, No.12, pp.6-11.

[33] Geisler T. (2016): Structure, functions and observations of behavior of elytra and wings of selected species of beetles (Coleoptera). - Czestochowa Entomological Circle Bulletin, No.14, pp.3-13.

[34] Geisler T. and Topczewska S. (2015): Analysis of the wing mechanism movement parameters of selected beetle species (Coleoptera). - International Journal of Applied Mechanics and Engineering, vol.20, No.1, pp.53-64.

[35] Artobolewski J. J. (1988): Theory of Mechanisms and Machines. - Moskwa.

[36] Felis J., Jaworowski H. and Cieślik J. (2008): Analysis of Mechanisms. - Kraków: T.1, (Wyd.2, AGH) University of Science and Technology Press, $2^{\text {nd }}$ Ed.

[37] Gronowicz A., Miller S. and Twaróg W. (2000): Theory of mechanisms and machines, set of analysis and design problems. - Wrocław: P. Wr.

[38] Miller S. (1996): Theory of mechanisms and machines - analysis of physical systems. - Wrocław: Technical University of Wrocław.

Received: August 12, 2016

Revised: September 15, 2016 